www.jmscr.igmpublication.org

Index Copernicus Value: 79.54

ISSN (e)-2347-176x ISSN (p) 2455-0450

crossref DOI: https://dx.doi.org/10.18535/jmscr/v7i6.131

\title{
Neck height ratio is an important anthropometric predictor in metabolic syndrome
}

\author{
Authors \\ Dr Mamatha B Patil ${ }^{1}$, Dr Samarthana ${ }^{2 *}$ \\ *Corresponding Author \\ Dr Samarthana.V
}

\#31 $1^{\text {st }}$ main $3^{\text {rd }}$ stage $3^{\text {rd }}$ block Basaweshwaranagar Bangalore 560079 Karnataka India

\begin{abstract}
Introduction: Neck height ratio (NHtR) and NC (neck circumference) have been suggested to measure of upper body adiposity. NHtR has the advantage over $N C$, as it adjusts for the differences in height. The aim of this study was to evaluate the role of NC and NHtR as an independent predictor of MetS (metabolic syndrome) among Indians

Materials and Methods: Present study is a cross sectional observational study, undertaken at Rajarajeshwari Medical College and Hospital, Bangalore, included 50 individuals, 30-80 years age, without comorbidities who gave informed consent underwent clinical, anthropometric and biochemical assessment, presence of MetS was ascertained using ( NCEP ATP) 3 criteria.

Results: Patients with MetS in both sexes had significantly higher NC, NHtR, glycated HBAlC dyslipidaemia (elevated triglycerides, decreased HDL). The highest tertile of NC had significantly higher BMI, hypertriglyceridemia and MetS. BMI had the largest area under curve (AUC) for predicting MetS in males. NHtR had the highest AUC for predicting MetS in females. A logistic regression analysis, using MetS as the dependent variable, showed that the relationship between NC and MetS after adjusting for sex and age was statistically significant. NC of $>32 \mathrm{~cm} / \mathrm{m}$ and NHtR of $>20 \mathrm{~cm} / \mathrm{m}$ for both the genders were the best values in identifying MetS, it also showed that the relationship between NHtR and MetS was more significant.

Conclusion: NC and NHtR are important predictors of metabolic syndrome and neck height ratio has a higher predictive potential than $N C$.

Keywords: neck height ratio, neck circumference, metabolic syndrome, dyslipidaemia, Body mass index.
\end{abstract}

\section{Introduction}

Body composition and fat distribution are associated with complications such as insulin resistance (IR), dyslipidaemia, diabetes mellitus type 2, and cardiovascular diseases (CVD) in adults ${ }^{[1]}$

Imaging studies and dual energy X-ray absorptiometry (DEXA) are the gold standard tools for evaluating body adiposity, but they are not applicable in all situations ${ }^{[2]}$.

In clinical practice, anthropometric measurements such as body mass index (BMI), waist circumference (WC), and neck circumference (NC) are valued for being more accessible, making them easier to apply ${ }^{[3]}$. Studies have shown that upper body obesity was more 
significantly associated with glucose intolerance hyperinsulinemia hypertriglyceridemia ${ }^{[4]}$.

In previous studies NC as an index of upper body obesity was found to be simple and time saving screening measure that can be used to identify overweight individuals ${ }^{[5]}$. $\mathrm{NC}$ is used as an alternative to $\mathrm{WC}$, as it is not affected by postprandial abdominal distension and respiratory movements, and has shown consistent results for excess subcutaneous fat in the upper body ${ }^{[2][7]}$. Neck height ratio (NHtR) has also been suggested to be a measure of upper body adiposity like NC. $\mathrm{NHtR}$ has the advantage over $\mathrm{NC}$, as it adjusts for the difference in $\mathrm{NC}$ attributable to differences in heights ${ }^{[8]}$

\section{Materials and Methods}

Present study is a hospital based cross sectional observational study, undertaken at Rajarajeshwari Medical College and Hospital, Bangalore,

\section{Inclusion Criteria}

50 individuals, 30-80 years age, without comorbidities who gave informed consent underwent clinical, anthropometric and biochemical assessment.

\section{Exclusion Criteria}

1) Cervical lymph nodes or deformities, neck swellings.

2) Type 1 diabetes, hypothyroidism, and hyperthyroidism

3) Patients on medications that can interfere with body composition and lipids such as anti-depressants, glucocorticoids, and anti-lipid medications

4) Patients not metabolically stable with uncontrolled blood glucose values on glucometer screening, viz. fasting/random blood glucose $>300 \mathrm{mg} / \mathrm{dl}$

- The collected blood samples were used for estimation of FBG, glycosylated haemoglobin $(\mathrm{HbA} 1 \mathrm{c} \%)$ and fasting lipid profile

- The presence of MetS was ascertained using the modified national cholesterol education program adult treatment panel
(NCEP ATP) III criteria (ethnic specific cut-offs for WC viz. $>90 \mathrm{~cm}$ in males and $>80 \mathrm{~cm}$ in females) with the presence of three or more risk factors were considered diagnostic i.e.

1) Central obesity (waist circumference $>90$ $\mathrm{cm}$ for males and $>80 \mathrm{~cm}$ for females)

2) Low HDL cholesterol (males $<40 \mathrm{mg} / \mathrm{dl}$ woman $<50 \mathrm{mg} / \mathrm{dl}$, or under treatment)

3) Triglycerides $(>150 \mathrm{mg} / \mathrm{dl}$, or under treatment)

4) Increased blood pressure $(>130 / 85 \mathrm{mmHg}$ or under treatment)

5) Fasting blood glucose $(>100 \mathrm{mg} / \mathrm{dL}$ or under treatment) (1)

- Height was measured in all individuals using a wall mounted stadiometer and body weight measured using an electronic calibrated scale.

- BMI was calculated as weight in kilograms divided by the square of height in meters $(\mathrm{kg} / \mathrm{m} 2)$.

- NC was measured using a calibrated plastic tape, with the head positioned along the Frankfurt plane, at middeck height, between the mid - cervical spine and mid - anterior neck, to within $1 \mathrm{~mm}$. In men with laryngeal prominence, it was measured just below the prominence. A single observer in triplicate made all measurements and the mean of three readings was taken

- WC was measured at the end of a gentle expiration midway between the lower rib margin and iliac crest with the patient standing with feet $23-30 \mathrm{~cm}$ apart.

- All participants underwent detailed general physical and systemic examination

\section{Stastical Analysis}

Normality of the distribution of variables was checked using the Kolmogorov-Smirnov test. Continuous variables were expressed as mean \pm standard deviation. $\mathrm{P}<0.05$ was considered as statistically significant. Chi-squared tests were used for categorical variables. 
Pearson's or Spearman's correlation coefficient was calculated for normally and nonnormally distributed variables, respectively.

For categorical data, frequencies, and percentages were estimated.

The associations between metabolic risk factors and anthropometric parameters were assessed using partial correlation analysis. Receiver operating characteristic (ROC) analyses were performed to assess the accuracy of the anthropometric parameters as diagnostic tests for detecting MetS and determine optimal sexspecific NC cut-offs in relation to MetS. The Youden index, defined as (sensitivity + specificity)-1 was used to determine the optimal cut-off points.

SPSS version 16 (Chicago, IL, USA) was used for statistical analysis.

\section{Results}

In this study 33 patients were normoglycemic and 17 were diabetic out of which males constituted $20 \%$ of the cohort (10/50) and females $14 \%(7 / 50)$ 16 cases were hypertensive and 23 had hypertriglyceridemia.

Males had a higher incidence of diabetes, hypertension, dyslipidaemia and metabolic syndrome they also had a higher NC compared to females.

Patients with MetS in both genders had significantly higher $\mathrm{NC}, \mathrm{NHtR}$ as compared to those without Mets. A NC of $>32 \mathrm{~cm} / \mathrm{m}$ (sensitivity $77.8 \%$ and specificity $80 \%$ ) for men and $>32 \mathrm{~cm} / \mathrm{m}$ (sensitivity $90 \%$ and specificity $81.8 \%$ ) for women were the best values in identifying MetS

Table 1 Baseline characteristics of the study population with regards to sex distribution and occurrence of metabolic syndrome $(\mathrm{n}=50)$

\begin{tabular}{|c|c|c|c|c|c|c|c|}
\hline \multirow[t]{2}{*}{ Parameter } & \multicolumn{3}{|c|}{ Males } & \multicolumn{3}{|c|}{ Females } & \multirow{2}{*}{$\begin{array}{c}\text { p-value } \\
\text { (males vs. } \\
\text { females) }\end{array}$} \\
\hline & All $(n=29)$ & $\begin{array}{l}\text { With MetS } \\
(\mathrm{n}=20)\end{array}$ & $\begin{array}{c}\text { Without MetS } \\
(\mathrm{n}=9)\end{array}$ & All $(n=21)$ & $\begin{array}{l}\text { With MetS } \\
(\mathrm{n}=11)\end{array}$ & $\begin{array}{l}\text { Without MetS } \\
(\mathrm{n}=10)\end{array}$ & \\
\hline Age & $57.00 \pm 12.510$ & $55.60 \pm 11.789$ & $58.50 \pm 13.518$ & $50.48 \pm 14.236$ & $51.38 \pm 13.711$ & $47.60 \pm 17.170$ & 0.092 \\
\hline HTN & $10(34.5 \%)$ & $4(26.7 \%)$ & $6(42.9 \%)$ & $6(28.6 \%)$ & $4(25 \%)$ & $2(40) \%)$. & 0.169 \\
\hline SBP & $135.72 \pm 10.885$ & $136.93 \pm 10.053$ & $134.43 \pm 11.953$ & $135.52 \pm 19.421$ & $135.63 \pm 22.202$ & $135.20 \pm 6.099$ & 0.035 \\
\hline DBP & $84.21 \pm 8.946$ & $84.93 \pm 9.059$ & $83.43 \pm 9.095$ & $80.48 \pm 7.891$ & $85.06 \pm 8.209$ & $70.00 \pm 5.0$ & 0.095 \\
\hline $\begin{array}{l}\text { Pre } \\
\text { DM/T2DM }\end{array}$ & $10(34.5 \%)$ & $5(33.3 \%)$ & $5(35.7 \%)$ & $7(33.3 \%)$ & $5(31.3 \%)$ & $2(40.0 \%)$ & $0.001 *$ \\
\hline BMI & $25.686 \pm 4.154$ & $25.973 \pm 4.8$ & $25.379 \pm 3.486$ & $24.49 \pm 3.847$ & $25.084 \pm 3.261$ & $24.304 \pm 4.092$ & 0.001 \\
\hline $\begin{array}{l}\text { Neck } \\
\text { circumference }\end{array}$ & $33.00 \pm 5.210$ & $33.13 \pm 5.370$ & $32.86 \pm 5.231$ & $30.10 \pm 5.957$ & $31.20 \pm 7.463$ & $29.75 \pm 5.651$ & $0.001 *$ \\
\hline $\mathrm{NHt}(\mathrm{cm} / \mathrm{m})$ & $20.398 \pm 2.756$ & $20.768 \pm 2.671$ & $20.0028 \pm 2.890$ & $20.08 \pm 3.248$ & $31.20 \pm 7.463$ & $21575 \pm 3.496$ & 0.117 \\
\hline FBS & $129.83 \pm 47.385$ & $115.53 \pm 37.828$ & $145.14 \pm 52.979$ & $132.62 \pm 61.839$ & $166.40 \pm 67.759$ & $122.06 \pm 58.096$ & 0.857 \\
\hline HBA1c & $8.145 \pm 10.8411$ & $9.673 \pm 15.05$ & $6.507 \pm 1.8248$ & $6.133 \pm 0.8132$ & $6.044 \pm 0.8809$ & $6.420 \pm 0.5119$ & 0.402 \\
\hline total chol & $170.59 \pm 47.593$ & $163.20 \pm 28.927$ & $178.50 \pm 62.026$ & $158.95 \pm 51.225$ & $163.69 \pm 56.493$ & $143.80 \pm 27.851$ & 0.413 \\
\hline $\begin{array}{l}\mathrm{HDL} \\
\mathrm{HDL}\end{array}$ & $36.66 \pm 14.403$ & $34.07 \pm 9.043$ & $39.43 \pm 18.513$ & $39.33 \pm 10.061$ & $33.40 \pm 8.735$ & $41.19 \pm 9.961$ & 0.468 \\
\hline triglycerides & $189.90 \pm 115.39$ & $205.73 \pm 142.25$ & $172.93 \pm 79.304$ & $153.33 \pm 67.101$ & $161.20 \pm 79.829$ & $150.88 \pm 65.398$ & 0.200 \\
\hline MetS & $20(69.0 \%)$ & & & $11(52.4 \%)$ & & & 0.001 \\
\hline
\end{tabular}

Table 2 Anthropometric and biochemical characteristics of the study studies as per the distribution of neck circumference

\begin{tabular}{|c|c|c|c|c|c|c|c|c|}
\hline \multirow[t]{3}{*}{ Parameters } & \multicolumn{4}{|c|}{ Males $(n=29)$} & \multicolumn{4}{|c|}{ Females $(\mathrm{n}=21)$} \\
\hline & \multicolumn{3}{|c|}{ Neck circumference } & \multirow[t]{2}{*}{ p-value } & \multicolumn{3}{|c|}{ Neck circumference } & \multirow[t]{2}{*}{ p-value } \\
\hline & $\begin{array}{c}<25^{\text {th }}(<34 \mathrm{~cm}) \\
(\mathrm{n}=12)\end{array}$ & $\begin{array}{l}25-75^{\text {th }}(34- \\
37.5)(\mathrm{n}=13)\end{array}$ & $\begin{array}{c}>75^{\text {th }}(>37.5) \\
(n=4)\end{array}$ & & $\begin{array}{c}<25^{\text {th }}(<34 \mathrm{~cm}) \\
(\mathrm{n}=17)\end{array}$ & $\begin{array}{l}25-75^{\text {th }}(34- \\
37.5)(n=4)\end{array}$ & $\begin{array}{c}>75^{\text {th }} \\
(>37.5) \\
(\mathrm{n}=0)\end{array}$ & \\
\hline Age & $62.08 \pm 11.39$ & $52.92 \pm 12.41$ & $55 \pm 13.68$ & 0.18 & $49.53 \pm 15.701$ & $54.5 \pm 3.109$ & - & 0.544 \\
\hline \multicolumn{9}{|c|}{ BMI } \\
\hline Normal $(<23 \mathrm{Kg})$ & $7(58.3 \%)$ & 0 & 0 & 0.001 & $7(41.2 \%)$ & $0(0.0 \%)$ & - & 0.001 \\
\hline Overweight $(23-27.5 \mathrm{Kg})$ & $3(25.0 \%)$ & $5(38.5 \%)$ & $2(50 \%)$ & 0.001 & $8(47.1 \%)$ & $3(75 \%)$ & - & 0.001 \\
\hline Obesity $(>27.5 \mathrm{~kg})$ & $2(16.7 \%)$ & $8(61.5 \%)$ & $2(50 \%)$ & 0.001 & $2(11.8 \%)$ & $1(25.0 \%)$ & - & 0.001 \\
\hline Pre DM/T2DM & $4(33.3 \%)$ & $3(23.1 \%)$ & $3(75 \%)$ & 0.16 & $4(23.5 \%)$ & $3(75.0 \%)$ & - & 0.08 \\
\hline MetS & $5(41.7 \%)$ & $11(84.6 \%)$ & $4(100.0 \%)$ & $<0.001$ & $7(41.2 \%)$ & $4(100.0 \%)$ & - & $<0.001$ \\
\hline hypertriglyceridemia & $3(25.0 \%)$ & $9(69.2 \%)$ & $3(75 \%)$ & 0.001 & $7(41.2 \%)$ & $1(25.0 \%)$ & - & 0.001 \\
\hline
\end{tabular}


Individuals were divided into subgroups based on NC tertile Individuals with higher NC had greater central obesity significantly more BMI, dysglycemia and males had higher triglyceride and significantly more incidence of METs

Similar observations were noted in studies by bennoun et al which showed that NC had positive correlation with traditional anthropometric indices like WC and BMI.
Neck circumference had a positive correlation with cardio metabolic risk factors hypertension dysglycemia dyslipidemia in both males and females and negative with HDL-C

These correlations grew stronger with $\mathrm{NHtR}$ and dysglycemia, TC and LDL-C, HDL-C in females and total cholesterol and HDL-C in males

Table 3 Correlation between anthrometric indices and cardio metabolic risk factors after adjusting of age

\begin{tabular}{|c|c|c|c|c|c|c|c|c|c|}
\hline Parameters & SBP & DBP & FBS & PPBS & HBA1c & $\begin{array}{c}\text { Total } \\
\text { cholestrol }\end{array}$ & HDL & LDL-C & VLDL \\
\hline \multicolumn{10}{|c|}{ Males(n=29) } \\
\hline SBP & 1 & $0.696^{* *}$ & 0.042 & 0.144 & -0.123 & 0.121 & 0.120 & -0.002 & -0.124 \\
\hline DBP & $0.696^{* *}$ & 1 & 0.037 & 0.152 & -0.297 & 0.108 & -0.003 & 0.110 & 0.493 \\
\hline FBS & 0.042 & 0.037 & 1 & $0.745^{* *}$ & -0.095 & 0.336 & -0.124 & $0.426^{*}$ & 0.832 \\
\hline PPBS & 0.144 & 0.152 & $0.745^{* *}$ & 1 & 0.122 & $0.386^{*}$ & -0.005 & $0.425^{*}$ & -0.521 \\
\hline HBA1c & -0.123 & -0.297 & -0.095 & 0.122 & 1 & 0.009 & 0.183 & 0.037 & -0.492 \\
\hline total chol & 0.121 & 0.108 & 0.336 & $0.386^{*}$ & 0.009 & 1 & $0.477^{* *}$ & $0.916^{* *}$ & -0.593 \\
\hline HDL & 0.120 & -0.003 & -0.124 & -0.005 & 0.183 & $0.477^{* * \pi}$ & 1 & 0.213 & -0.800 \\
\hline LDL-C & -0.002 & 0.110 & $0.426^{*}$ & $0.425^{*}$ & 0.037 & $0.916^{* *}$ & 0.213 & 1 & 0.220 \\
\hline VLDL & -0.124 & 0.493 & 0.832 & -0.521 & -0.492 & -0.593 & -0.800 & 0.220 & 1 \\
\hline \multicolumn{10}{|c|}{ Females $(\mathrm{n}=21)$} \\
\hline SBP & 1 & 0.334 & 0.062 & -0.073 & -0.152 & 0.025 & -0.180 & 0.012 & 0.357 \\
\hline DBP & 0.334 & 1 & $0.536^{*}$ & $0.604^{* * *}$ & 0.301 & 0.013 & -0.226 & 0.240 & -0.072 \\
\hline FBS & 0.062 & $0.536^{*}$ & 1 & $0.836^{* *}$ & $0.765^{* *}$ & -0.243 & $-0.599^{* *}$ & -0.098 & 0.757 \\
\hline PPBS & -0.073 & $0.604^{* *}$ & $0.836^{* *}$ & 1 & $0.790^{* *}$ & -0.261 & $-0.539^{*}$ & -0.031 & 0.648 \\
\hline HBA1c & -0.152 & 0.301 & $0.765^{* *}$ & $0.790^{* * *}$ & 1 & -0.296 & -0.327 & -0.128 & 0.329 \\
\hline total chol & 0.025 & 0.013 & -0.243 & -0.261 & -0.296 & 1 & 0.311 & $0.642^{* *}$ & -0.270 \\
\hline HDL & -0.180 & -0.226 & $-0.599^{* *}$ & $-0.539^{*}$ & -0.327 & 0.311 & 1 & 0.338 & -0.666 \\
\hline LDL-C & 0.012 & 0.240 & -0.098 & -0.031 & -0.128 & $0.642^{* *}$ & 0.338 & 1 & -0.428 \\
\hline VLDL & 0.357 & -0.072 & 0.757 & 0.648 & 0.329 & -0.270 & -0.666 & -0.428 & 1 \\
\hline
\end{tabular}

**Correlation is significant at the 0.01 level (2-tailed)

*Correlation is significant at the 0.05 level (2-tailed).

Table 4 Area under the ROC by different anthropometric indices as pre diabetics of metabolic syndrome and cardio metabolic risk factors $(n=50)$

\begin{tabular}{|c|c|c|c|c|c|c|c|c|}
\hline \multirow[t]{2}{*}{ Parameters } & \multicolumn{2}{|l|}{$\mathrm{NC}$} & \multicolumn{2}{|l|}{ WC } & \multicolumn{2}{|l|}{ NHtR } & \multicolumn{2}{|l|}{ BMI } \\
\hline & AUC(95\%CI) & P value & AUC $(95 \% \mathrm{CI})$ & $P$ value & $\mathrm{AUC}(95 \% \mathrm{CI})$ & $P$ value & $\mathrm{AUC}(95 \% \mathrm{CI})$ & $P$ value \\
\hline \multicolumn{9}{|l|}{ Males $(\mathrm{n}=29)$} \\
\hline MetS & $\begin{array}{c}0.471(0.257- \\
0.685)\end{array}$ & $<0.001$ & $\begin{array}{c}.414(0.203- \\
0.626)\end{array}$ & 0.001 & $0.364(0.156-0.57)$ & 0.001 & $\begin{array}{c}0.483(0.267- \\
0.699)\end{array}$ & $<0.001$ \\
\hline Pre DM/T2DM & $.387(0.153-0.62)$ & 0.024 & $.539(0.313-0.76)$ & 0.65 & $\begin{array}{c}.424(0.202- \\
0.646)\end{array}$ & 0.075 & $.518(0.296-0.74)$ & 0.002 \\
\hline HTN & $\begin{array}{c}.521(0.287- \\
0.755) \\
\end{array}$ & 0.554 & $\begin{array}{c}.582(0.338- \\
0.825) \\
\end{array}$ & 0.650 & $.574(0.348-0.8)$ & .521 & $\begin{array}{c}.550(0.328- \\
0.772) \\
\end{array}$ & 0.663 \\
\hline Hypertriglyceridemia & $.205(0.039-0.37)$ & $<0.001$ & $\begin{array}{c}.231(0.051- \\
0.411)\end{array}$ & 0.014 & $\begin{array}{c}.138(0.005- \\
0.271)\end{array}$ & .001 & $\begin{array}{c}.333(0.122- \\
0.544)\end{array}$ & 0.127 \\
\hline \multicolumn{9}{|l|}{ Females $(n=21)$} \\
\hline MetS & $\begin{array}{c}0.675(0.364- \\
0.986)\end{array}$ & $<0.001$ & $0.562(0.24-0.885)$ & $<0.001$ & $\begin{array}{c}0.713(0.472- \\
0.953)\end{array}$ & 0.160 & $\begin{array}{c}0.587(0.288- \\
0.887)\end{array}$ & 0.001 \\
\hline Pre DM/T2DM & $.291(0.027-0.55)$ & 0.026 & $.362(0.115-0.61)$ & 0.314 & $.230(0.0-0.478)$ & .048 & $\begin{array}{c}.265(0.039- \\
0.491)\end{array}$ & .086 \\
\hline HTN & $\begin{array}{c}.433(0.154- \\
0.713) \\
\end{array}$ & 0.540 & $\begin{array}{c}.339(0.105- \\
0.573) \\
\end{array}$ & $<0.001$ & $.450(0.170-0.73)$ & .726 & $\begin{array}{c}.256(0.045- \\
0.466)\end{array}$ & .087 \\
\hline Hypertriglyceridemia & $.255(0.065-0.471)$ & 0.025 & $\begin{array}{c}.274(0.051- \\
0.497)\end{array}$ & 0.069 & $\begin{array}{c}.293(0.069- \\
0.518)\end{array}$ & .119 & $.144(0.0-0.313)$ & .007 \\
\hline
\end{tabular}

The area under curve was constructed(AUC) to evaluate the predictive values of anthropometric indices for MetS and its components

-The AUC for NHtR predicting MetS in males and females was 0.364 and 0.713 respectively.

-BMI had the highest AUC for predicting MetS in males and NHtR had the highest AUC for females

$\cdot 3$ out of 20 males and one out of 11 females with MetS had normal WC but a higher NC and NHtR. 


\section{Discussion}

Visceral fat and abdominal subcutaneous fat has been traditionally measured using WC and WC is used as the standard index to identify patients with Metabolic syndrome in studies done by Cornier et $\mathrm{al}^{[10]}$. Studies by Aswathappa et al have shown that WC fails to identify a significant proportion of patients with cardiovascular diseases. Studies have shown that upper body subcutaneous fat is responsible for a much larger proportion of systemic free fatty acid release and then visceral fat as it is lipolytically more active than lower body adipose tissue ${ }^{[11]}$ hence it may have a significant correlation to insulin resistance and dyslipidemia. Studies by Yang GR et al and Dutta et have used $\mathrm{NC}$ as an index of upper body subcutaneous fat and has been correlated with various cardiovascular risk factors ${ }^{[12][13]}$. Preis et al followed up participants from the Framingham heart study and noted NC correlated with development of multiple cardiovascular risk factors, it was found that $\mathrm{NC}$ was associated with CVD risk factors even after adjustment for VAT and BMI thus suggesting upper body fat may be a unique pathogenic fat depot ${ }^{[14]}$

In this study patients with metabolic syndrome had significantly higher NC, it had a positive correlation with cardio metabolic risk factors like hypertension dysglycemia and dyslipidemia which was in line with the studies by Grundy Scott et $\mathrm{al}^{[8][15]}$. NHtR ratio was better correlated with the above cardiovascular risk factors, this observation was in accordance with previous studies by Selvan et $\mathrm{al}^{[8]}$. BMI had the highest area under the curve for predicting MetS in males and NHtR had the highest AUC for females. NC and NHtR had a higher sensitivity in predicting patients with metabolic syndrome

A $\mathrm{NC}$ of $>32 \mathrm{~cm} / \mathrm{m}$ (sensitivity $77.8 \%$ and specificity $80 \%$ ) for men and $>32 \mathrm{~cm} / \mathrm{m}$ (sensitivity $90 \%$ and specificity $81.8 \%$ ) for women were the best values in identifying MetS similar results were found in previous studies by Ben noun et al and De Silva et $\mathrm{al}^{[6][2]}$.
A logistic regression analysis, using MetS as the dependent variable, showed that the relationship between NC and MetS after adjusting for sex and age was statistically significant (odds ratio 1.561 [95\% confidence interval [CI]: 0.83-1.112]; P $=0.001$ ).

Similarly, a NHtR of $>20 \mathrm{~cm} / \mathrm{m}$ (sensitivity $66.7 \%$ and specificity 95\%) for men and $>20 \mathrm{~cm} / \mathrm{m}$ (sensitivity $80 \%$ and specificity $75.3 \%$ ) for women were the best values of combined sensitivity and specificity in identifying MetS.

A logistic regression analysis, using MetS as the dependent variable, showed that the relationship between NHtR and MetS after adjusting for sex and age was statistically significant (odds ratio 1.951[95\% CI: 0.772-1.336]; $\mathrm{p}=0.001$ )

$\mathrm{NC}$ and NHtR are good predictors of MetS and cardiovascular risk factors in Asian Indians. NHtR is more reliable and a better parameter than NC $\mathrm{NC}$ and NHtR are convenient to measure as there is no need of any privacy for the patient as compared to WC and waist height ratio which may be socially less acceptable during community screening and certain circumstances

\section{Conclusion}

$\mathrm{NC}$ and NHtR are good predictors of MetS and cardiovascular risk factors in Asian Indians. NHtR is more reliable and a better parameter than $\mathrm{NC}$ $\mathrm{NC}$ and $\mathrm{NHtR}$ are convenient to measure as there is no need of any privacy for the patient as compared to $\mathrm{WC}$ and waist height ratio which may be socially less acceptable during community screening and certain circumstances

\section{References}

1. Kissebah AH, Vydelingum N, Murray R, Evans DJ, Hartz AJ, Kalkhoff RK, et al. Relation of body fat distribution to metabolic complications of obesity. J Clin Endocrinol Metab. 1982 Feb;54(2):25460.

2. da Silva C de C, Zambon MP, Vasques ACJ, Rodrigues AM de B, Camilo DF, Antonio MÂR de GM, et al. Neck 
circumference as a new anthropometric indicator for prediction of insulin resistance and components of metabolic syndrome in adolescents: Brazilian Metabolic Syndrome Study. Rev Paul Pediatr Orgao Of Soc Pediatr Sao Paulo. 2014 Jun;32(2):221-9.

3. Fujimoto WY, Bergstrom RW, Boyko EJ, Chen KW, Leonetti DL, Newell-Morris L, et al. Visceral adiposity and incident coronary heart disease in JapaneseAmerican men. The 10-year follow-up results of the Seattle Japanese-American Community Diabetes Study. Diabetes Care. 1999 Nov;22(11):1808-12.

4. Laakso M, Matilainen V, KeinänenKiukaanniemi S. Association of neck circumference with insulin resistancerelated factors. Int $\mathbf{J}$ Obes Relat Metab Disord J Int Assoc Study Obes. 2002 Jun;26(6):873-5.

5. Ben-Noun L, Sohar E, Laor A. Neck circumference as a simple screening measure for identifying overweight and obese patients. Obes Res. 2001 Aug;9(8):470-7.

6. Ben-Noun L, Laor A. Relationship of neck circumference to cardiovascular risk factors. Obes Res. 2003 Feb;11(2):226-31.

7. Effects of body fat distribution on regional lipolysis in obesity. [Internet]. [cited 2019 May 20]. Available from: https://www.ncbi.nlm.nih.gov/pmc/articles /PMC295396/

8. Selvan C, Dutta D, Thukral A, Nargis T, Kumar M, Mukhopadhyay S, et al. Neck height ratio is an important predictor of metabolic syndrome among Asian Indians. Indian J Endocrinol Metab. 2016 Dec;20(6):831-7.

9. Grundy Scott M., Cleeman James I., Daniels Stephen R., Donato Karen A., Eckel Robert H., Franklin Barry A., et al. Diagnosis and Management of the
Metabolic Syndrome. Circulation. 2005 Oct 25;112(17):2735-52.

10. Cornier M-A, Després J-P, Davis N, Grossniklaus DA, Klein S, Lamarche B, et al. Assessing adiposity: a scientific statement from the American Heart Association. Circulation. 2011 Nov 1;124(18):1996-2019.

11. Aswathappa J, Garg S, Kutty K, Shankar V. Neck circumference as an anthropometric measure of obesity in diabetics. North Am J Med Sci. 2013 Jan;5(1):28-31.

12. Yang G-R, Yuan S-Y, Fu H-J, Wan G, Zhu L-X, Bu X-L, et al. Neck circumference positively related with central obesity, overweight, and metabolic syndrome in Chinese subjects with type 2 diabetes: Beijing Community Diabetes Study 4. Diabetes Care. 2010 Nov;33(11):2465-7.

13. Urinary albumin : creatinine ratio predicts prediabetes progression to diabetes and reversal to normoglycemia: Role of associated insulin resistance, inflammatory cytokines and low vitamin D - Dutta 2014 - Journal of Diabetes - Wiley Online Library [Internet]. [cited 2019 May 19]. Available from: https://onlinelibrary.wiley.com/doi/pdf/10. 1111/1753-0407.12112

14. Preis SR, Massaro JM, Hoffmann U, D'Agostino RB, Sr, Levy D, et al. Neck Circumference as a Novel Measure of Cardiometabolic Risk: The Framingham Heart Study. J Clin Endocrinol Metab. 2010 Aug;95(8):3701.

15. Stabe C, Vasques ACJ, Lima MMO, Tambascia MA, Pareja JC, Yamanaka A, et al. Neck circumference as a simple tool for identifying the metabolic syndrome and insulin resistance: results from the Brazilian Metabolic Syndrome Study. Clin Endocrinol (Oxf). 2013 Jun;78(6):874-81. 